\title{
Mulheres na Tecnologia da Informação: Histórico e Cenário Atual nos Cursos Superiores
}

\author{
Vívian Ludimila Aguiar Santos ${ }^{1}$, Thales Francisco Mota Carvalho², Maria do \\ Socorro Vieira Barreto ${ }^{1}$
}

${ }^{1}$ Instituto Federal do Norte de Minas Gerais (IFNMG)

CEP 39274-140 - Pirapora, MG - Brasil

${ }^{2}$ Universidade Federal dos Vales do Jequitinhonha e Mucuri (UFVJM)

CEP 39100-100 - Diamantina, MG - Brasil

vivian.santoseifnmg.edu.br, thales.mota@ufvjm.edu.br,

socorro.barretodifnmg.edu.br

\begin{abstract}
The objective of this work is to highlight the history of female participation in the Information Technology (IT) area and to highlight the current female scenario of higher education courses in IT in Brazil. For this, we conducted a bibliographic search and an analysis of the microdata referring to the Higher Education Census from 2014 to 2019, made available by the National Institute of Educational Studies and Research Anisio Teixeira (INEP). The results indicate the low representation of women in IT Higher Education Courses in Brazil, during the studied period.
\end{abstract}

Resumo. $O$ objetivo deste trabalho é salientar o histórico da participação feminina na área de Tecnologia da Informação (TI) e destacar o cenário feminino atual dos cursos superiores de TI no Brasil. Para isso, realizou-se uma pesquisa bibliográfica e uma análise dos microdados referentes ao Censo da Educação Superior do período de 2014 a 2019, disponibilizados pelo Instituto Nacional de Estudos e Pesquisas Educacionais Anísio Teixeira (INEP). Os resultados indicam a baixa representatividade feminina nos Cursos Superiores de TI no Brasil, durante o periodo estudado.

\section{Introdução}

A Tecnologia da Informação (TI) é uma área com crescente demanda de profissionais. Entretanto, observa-se que o número de estudantes e profissionais do sexo feminino atuantes nesta área é expressivamente menor do que o número de homens [Nunes, 2017]. Dessa forma, a participação feminina nos cursos da área de TI é amplamente estudada, uma vez que, historicamente, a TI se caracterizou como uma atividade notavelmente masculina [Moreira et al., 2014].

Na evolução da ciência, a participação feminina ocorreu aos poucos, e mesmo assim, quando alguma mulher teve uma importância substancial na história científica, ao se registrarem os fatos houve uma inviabilização da sua participação [Oliveira et al., 2014]. Diante desse contexto, entende-se que a contribuição feminina em ciência e tecnologia tem sido negligenciada, sendo marcada por estereótipos de gêneros que dificultam a entrada de mulheres na área [Maia, 2016]. 
Existem muitos estudos que buscam compreender os fatores que levaram à diminuição do número de mulheres na área de TI [Louzada et al., 2014]. Castro [2013] aponta questões culturais e educacionais visto que desde criança, as mulheres são influenciadas a gostar de outros assuntos, mais aceitáveis ao papel de gênero que foi socialmente construído, como tarefas que envolvam cuidado e comunicação.

Nessa discussão, é relevante destacar que mesmo com o aumento da presença de mulheres inseridas no ensino superior, a preferência feminina continuou sendo nos campos tradicionalmente considerados femininos. Tal fato mostra que as diferenças de gêneros na qual fomos submetidas historicamente, ainda influenciam a formação do vínculo com o conhecimento [Lima, 2013].

Dada a perspectiva da existência de poucas mulheres na área de TI, o objetivo geral desta pesquisa é salientar a importância da participação feminina nesta área. E os objetivos específicos são: destacar o histórico feminino na evolução de TI e apresentar o cenário feminino atual dos cursos superiores de TI no Brasil, no período 2014 a 2019.

Esta pesquisa, ao apontar o cenário atual de inserção das mulheres na área da TI e evidenciar o seu papel histórico, busca contribuir com o debate em torno da desigualdade de gênero nos cursos superiores de TI, e com a formulação de políticas públicas de inclusão de gênero. Além disso, ao revelar a omissão de mulheres na história da ciência pretende desconstruir a ideia de que o campo da informática seja apenas para homens.

Para responder aos objetivos propostos, foi feita uma pesquisa bibliográfica visando fundamentar teoricamente o estudo [Gil, 2008]. O sistema de busca adotou as seguintes palavras chaves: mulheres na TI, desigualdade de gênero na TI, histórico feminino na TI e mulheres nos cursos superiores de TI. Adotou-se também a pesquisa documental [Gil, 2008], por meio da qual foram analisados dados extraídos da base de microdados do portal do Instituto Nacional de Estudos e Pesquisas Educacionais Anísio Teixeira (INEP). Dentre os dados abertos disponibilizados pelo portal estão os microdados do Censo da Educação Superior, os quais constituem o objeto de pesquisa deste trabalho [INEP, 2021]. Para realizar uma análise estatística descritiva dos dados, um algoritmo foi desenvolvido utilizando a linguagem de programação Python ${ }^{1}$, uma vez que algumas planilhas disponibilizadas pelo INEP contêm mais de 12 milhões de linhas dificultando sua análise em softwares como Microsoft Excel e LibreOffice Calc.

Devida a grande variação dos nomes dos cursos da área de TI, os cursos analisados foram divididos em 6 grupos: (i) Redes de Computadores, (ii) Análise e Desenvolvimento de Sistemas, (iii) Engenharia da Computação, (iv) Ciências da Computação, (v) Sistemas de Informação e (vi) outros (i.e., Tecnologias Digitais, Computação e Informática, Gerenciamento de Redes de Computadores, Segurança da Informação, Análise e Desenvolvimento de Sistemas Internet, Desenvolvimento de Sistemas de Informação, Gestão da Tecnologia da Informação, Sistemas para Internet, Engenharia de Software, Informática, Computação). Posteriormente, os estudantes de todos esses cursos foram separados em duas categorias: sexo feminino e sexo masculino. Dessa forma, observou-se a quantidade de discentes de cada sexo nos cursos da área de TI de forma geral e também separados pelos grupos de cursos.

1 https://www.python.org/ 


\section{Histórico Feminino na Área de TI}

Têm-se na história da informática, diversas mulheres com contribuições significativas e revolucionárias. Observa-se que as primeiras pessoas que definiram o ritmo da computação de máquinas programáveis foram mulheres [Light,1999].

Pode-se citar como pioneira Augusta Ada Byron King, condessa de Lovelace, atualmente conhecida como Ada Lovelace, uma matemática e escritora inglesa, a qual atuou no Século XIX. Ada escreveu o primeiro algoritmo para ser processado por uma máquina, a máquina analítica de Charles Babbage ${ }^{2}$ [Fuegi e Francis, 2003]. Por esse trabalho é considerada a primeira programadora de toda a história. Ela também elaborou vários programas para calcular funções analíticas, bem como o programa para calcular a sequência de Bernoulli ${ }^{3}$ [Huskey e Huskey, 1980]. Porém, o seu trabalho só foi reconhecido mais de cem anos depois de sua morte. A linguagem de programação Ada foi criada em sua homenagem nos Estados Unidos da América (EUA) [Stein, 1985].

Outro caso famoso em que as mulheres foram apagadas da história da computação, é a invenção do primeiro computador digital eletrônico de grande escala, o Electronic Numerical Integrator and Computer (ENIAC, em português, computador integrador numérico eletrônico) [Mccartney, 1999]. De acordo com Light [1999], durante a Segunda Guerra Mundial, quase 200 jovens mulheres trabalharam como computadores humanos, conhecidas como computadoras, realizando cálculos de balística (calculando manualmente a trajetória de mísseis desde o momento em que saíam dos canhões até atingirem seus alvos). O trabalho exigia um alto nível de habilidade matemática, que incluía a resolução de equações diferenciais não lineares em muitas variáveis. Como cada cálculo era muito demorado, gastava em média 30 horas, o exército resolveu financiar um experimento altamente arriscado: uma máquina que pudesse realizar as equações em uma fração do tempo que as computadoras levavam. Desta forma surgiu o projeto ENIAC.

Em 1945, pouco tempo antes do ENIAC ficar pronto, seis computadoras foram escolhidas para o que era considerado um trabalho inferior: descobrir como a máquina funcionava e como ela deveria ser programada para executar os cálculos balísticos. As matemáticas selecionadas foram: Frances Bilas, Jean Jennings, Ruth Lichterman, Kathleen McNulty, Betty Snyder e Marlyn Wescoff. Depois de alguns meses, os cálculos balísticos passaram a ser resolvidos em 15 segundos pelo ENIAC [Bittencourt, 2016]. O projeto ENIAC fez uma distinção fundamental entre hardware e software: projetar hardware era tarefa de um homem; programação era o trabalho de uma mulher. Cada uma dessas partes de gênero do projeto tinha sua própria classificação de status clara. O software, uma tarefa secundária e administrativa, não correspondia à importância de construir o ENIAC e fazê-lo funcionar [Light,1999].

O ENIAC abriu caminho para o desenvolvimento dos computadores, que em 60 anos passaram de toneladas e um custo de 500 mil dólares a menos de 2 quilos e mil

2 A máquina analítica de Charles Babbage incorporava uma unidade lógica aritmética, fluxo de controle na forma de ramificações condicionais, loops e memória integrada, tornando-o o primeiro projeto para um computador de uso geral que poderia ser descrito em termos modernos [GRAHAM-CUMMING, 2010].

3 Números de Bernoulli são sequências de números racionais com profundas conexões na teoria dos números. São definidos como os coeficientes da Expansão de Taylor [MIRKOSKI, 2018]. 
dólares. Parte importante disso foi o desenvolvimento dos transístores, que substituíram os tubos de vácuo e simplificaram o processo [Wazlawick, 2017].

No entanto, foram os engenheiros e oficiais do exército que receberam crédito pela invenção do ENIAC. E as seis mulheres computadores escolhidas para operá-lo ficaram de fora da condecoração. As seis operadoras entendiam não apenas a matemática da computação, mas a própria máquina. $\mathrm{O}$ fato de os líderes e historiadores do projeto não valorizarem seu conhecimento técnico se encaixa na percepção acadêmica de uma contradição entre o trabalho realmente realizado pelas mulheres e a maneira como os outros avaliam esse trabalho. A omissão de mulheres da história da ciência da computação perpetua os conceitos errôneos de mulheres como desinteressadas ou incapazes na área [Light,1999].

Após 50 anos do lançamento do ENIAC, em 1996, Kathy Kleiman, uma formanda da Universidade de Harvard decidiu gravar as histórias das programadoras e lutar pelos seus reconhecimentos públicos. Por causa de Kathy, as seis programadoras do ENIAC foram promovidas pela Women in Technology International (WITI) ${ }^{4}$ durante a conferência Women in Technology de 1997. Nos anos seguintes, elas também receberam prêmios da IEEE Computer Society ${ }^{5}$ e do Computing History Museum ${ }^{6}$.

Ainda no século XX, com o projeto Mark I, o primeiro computador usado para as curvas de voo dos foguetes da Segunda Guerra Mundial foi computado. Uma das primeiras programadoras do computador Mark I, foi Grace Murray Hopper. Ela era uma cientista da computação americana e contra-almirante da Marinha dos EUA, que liderou a programação do Mark $I$. Hopper contribuiu para o desenvolvimento da linguagem COBOL (um acrônimo para COmmon Business-Oriented Language, em português, Linguagem Comum Orientada para os Negócios). Ela projetou a COBOL, para que fosse uma linguagem de programação compreensível e desenvolveu o primeiro compilador para esta linguagem [Schinzel, 2017]. Além disso, de acordo com Williams [2012], Hopper é autora do termo "bug" usado para referir a uma falha em código-fonte. Quando procurava um problema em seu computador, percebeu que havia um inseto morto no computador causando transtorno, desde então o termo bug passou a ser usado no âmbito da tecnologia.

Outra mulher pioneira ligada à guerra foi Hedy Lamar. Em 1937, ela fugiu do marido Fritz Mandl, que era produtor de armas, porque não suportava o ciúme dele, e foi para os EUA. Durante a Segunda Guerra Mundial, ela que era judia, queria lutar contra os alemães, aproveitando seu conhecimento sobre telegrafia, usou essa técnica para torpedos de direção, que não podiam ser rastreados. Logo, esta foi a sua mais significativa contribuição tecnológica [Barton, 2010]. Hoje, esse método é usado para

${ }^{4}$ WITI é uma organização não governamental que promove as realizações das mulheres em tecnologia, fornecendo suporte, oportunidades, inspiração, notícias, oportunidades de carreira, artigos e informações para capacitar as mulheres por meio da tecnologia [WITI, 2020].

5 IEEE Computer Society é uma sociedade profissional do Instituto de Engenheiros Elétricos e Eletrônicos. Tem como objetivo avançar a teoria, a prática e a aplicação da ciência e tecnologia do computador e do processamento de informações e a posição profissional de seus membros [IEEE, 2020].

${ }^{6}$ O museu apresenta histórias e artefatos da era da informação e explora a revolução da computação e seu impacto na sociedade. Oferecem workshops, eventos e passeios, bem como recursos autoguiados que introduzem conceitos tecnológicos [CHM, 2020]. 
todas as comunicações entre celulares, radiocomunicação, bluetooth, internet móvel etc., para torná-lo seguro. Ou seja, esse sistema de comunicações serviu de base para a atual telefonia celular [Schinzel, 2017].

Além da linguagem de programação COBOL desenvolvida pela Grace Hopper, na década de 1950, outra mulher, Jean Sammet desenvolveu a linguagem de programação, a FORMAC, acrônimo para FORmula MAnipulation Compiler, que é uma extensão da linguagem FORTRAN. Sammet também escreveu o primeiro livro sobre linguagens de programação [Sammet, 1969]. Em 1970, Adele Goldberg e Alan Kay desenvolveram o Smalltalk-80, que ainda é considerado uma excelente linguagem de programação, antecipando a orientação a objetos [Kay, 1996].

Destaca-se que na década de 1960, enquanto o desenvolvimento de hardware era uma tarefa masculina, a programação, menos respeitada, era feminina. Dessa forma, a programação era realizada por uma alta porcentagem de mulheres e, quando a Ciência da Computação passou a ser uma disciplina científica, um quarto dos estudantes que começavam a estudar o curso era do sexo feminino. A participação feminina em Ciência da Computação quebrou-se em meados da década de 1980, à medida que o software e a TI se tornaram importantes fatores econômicos e sociais, com a introdução de computadores domésticos em residências (PCs), a programação e o desenvolvimento de software passaram de mulheres para mãos masculinas e, assim, a participação feminina caiu consideravelmente [Schinzel, 2017].

\section{Inserção de Mulheres nos Cursos Superiores de TI no Brasil}

Para realizar a análise dos microdados do Censo da Educação Superior foram selecionados os dados dos últimos seis anos (2014 a 2019) disponibilizados no portal do INEP. Conforme explicado, todos os cursos da área de TI foram agregados em 5 grupos. Além disso, os discentes foram categorizados em duas classes: cursando e formados.

A Figura 1 confirma a diferença entre a quantidade de discentes do sexo feminino e masculino nos cursos de TI. A Figura 1(A) mostra o número dos que estão cursando e a Figura 1(B) mostra o número de formados. Percebe-se que o número de mulheres foi menor em todos os anos. Considerando os dados dos 6 anos pesquisados, tem-se que apenas $13,8 \%$ e $15,2 \%$ são mulheres cursando e formadas, respectivamente.

A Figura 2 mostra a quantidade de discentes femininas de TI, de acordo com a separação dos cursos, ao longo dos anos de 2014 a 2019. É possível verificar que entre os cursos, o mais escolhido pelas mulheres foi Sistemas de Informação (SI), de 2014 até 2018, e que o menos escolhido foi Rede de Computadores (RC), por todo o período. Entretanto, devido a uma diminuição no número de alunas em SI, ao longo de todo período, percebe-se que a partir de 2018, o número de mulheres em Análise e Desenvolvimento de Sistemas (ADS) ultrapassou o número de SI, tornando-se o curso com maior preferência para as meninas. Nota-se, ainda, que o número de mulheres em Engenharia da Computação (EC) teve um leve aumento, em Ciência da Computação (CC) manteve-se praticamente constante e em Outros diminuiu, com o passar dos anos.

A Figura 3 apresenta a quantidade de mulheres formadas em TI, por curso, no período de 2014 a 2019. Observa-se que o número de formadas em EC aumentou, em CC manteve-se praticamente constante e nos demais cursos, esse número diminuiu. Novamente, verifica-se que o número de formadas em SI tem decrescido desde 2016, sendo ultrapassado pelo número de formadas em ADS a partir de 2018. 


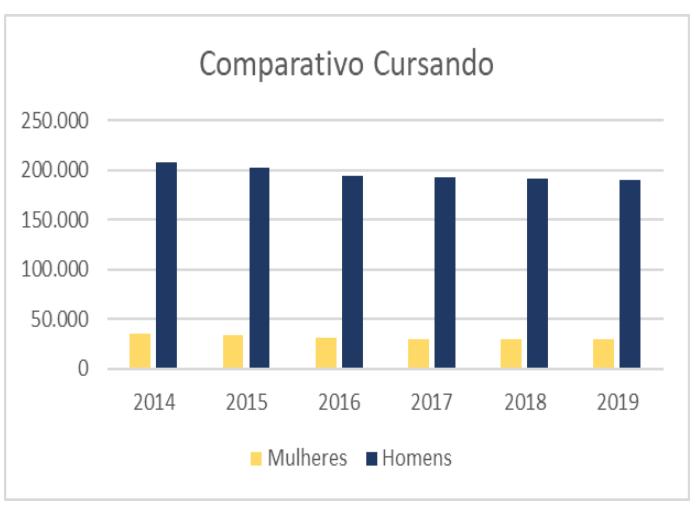

(A)

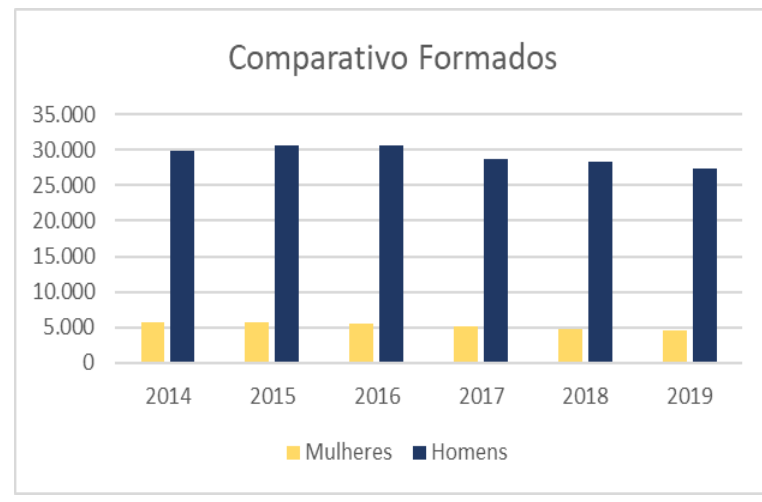

(B)

Figura 1. Quantidade de alunos cursando e formados de TI nos anos de 2014 a 2019.

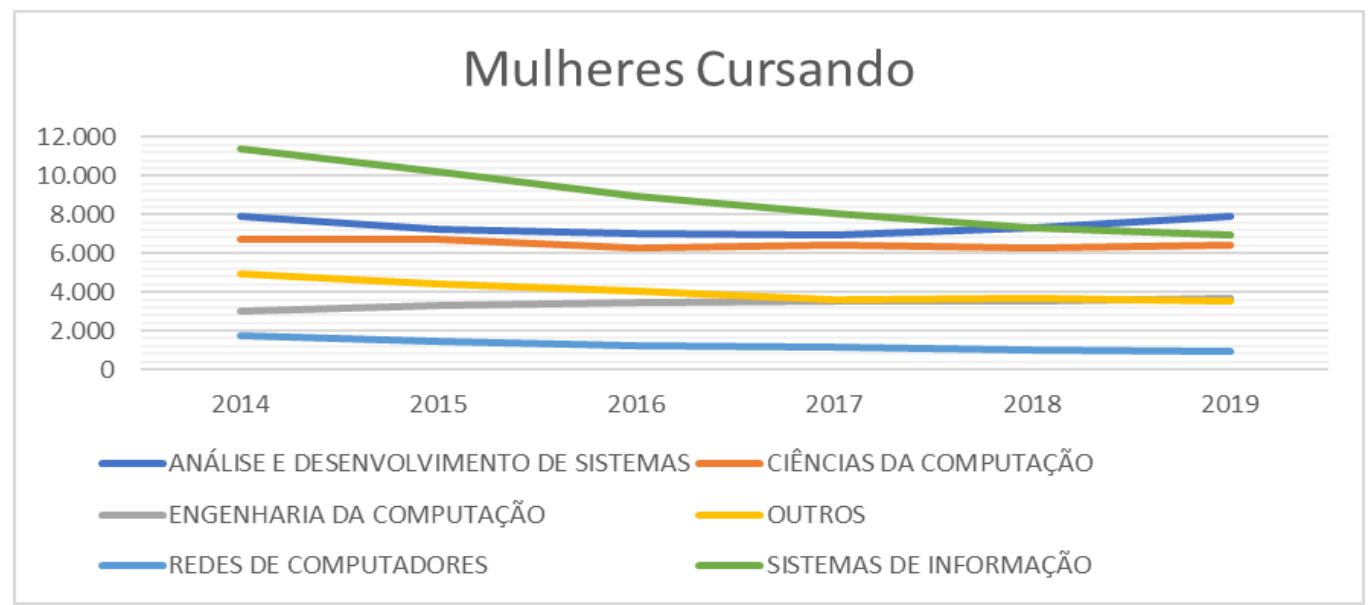

Figura 2. Quantidade de mulheres cursando TI nos anos de 2014 a 2019.

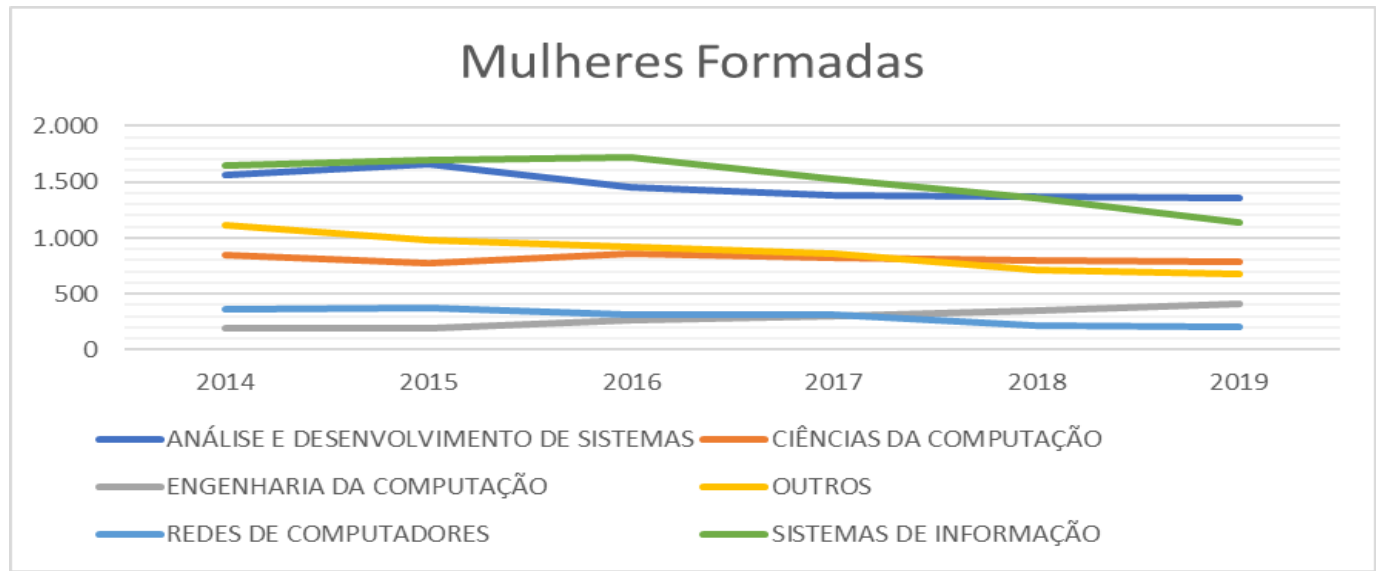

Figura 3. Quantidade de mulheres formadas em TI nos anos de 2014 a 2019.

A Figura 4 demonstra a desigualdade entre mulheres e homens, destacando quais cursos de TI que estão cursando (2018-2019). A partir de uma perspectiva geral, para cada curso, em 2018 (Figura 4A), a média de discentes femininas é de apenas 13,4\% e em 2019 (Figura 4B), esta média é de 13,5\%. Percebe-se, ainda, que a maior diferença é encontrada no curso de RC, onde os homens representam $90 \%$ dos discentes. $\mathrm{E}$ a menor diferença, nos cursos agrupados como Outros, em que os homens representam $80 \%$. 
A Figura 5 ressalta em quais cursos de TI os discentes formaram em 2018 e 2019. Mais uma vez, fica representado a desigualdade de gênero nos cursos de TI. Em 2018 (Figura 5A) a média de mulheres formadas é de 13,9\% em cada grupo de cursos. Já em 2019 (Figura 5B) esta média de mulheres formadas é de 14,0\% em cada grupo.

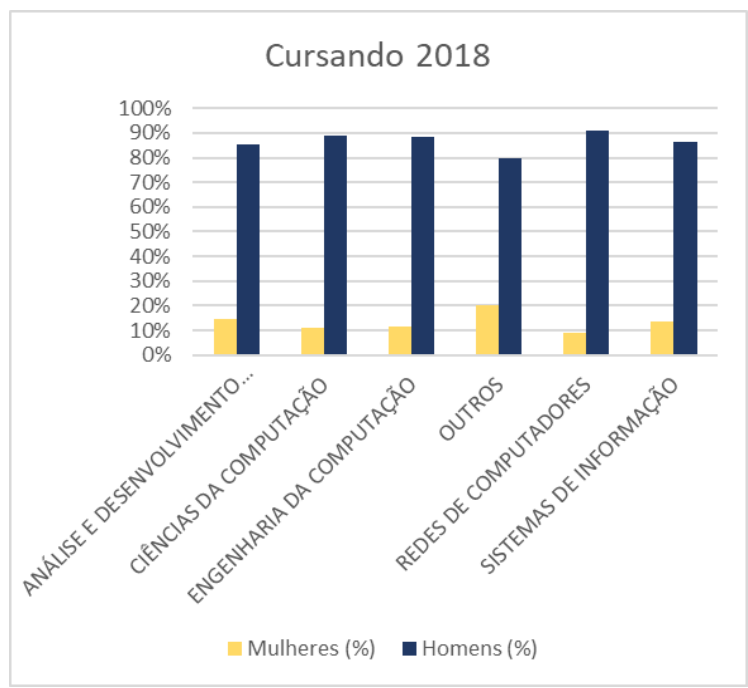

(A)

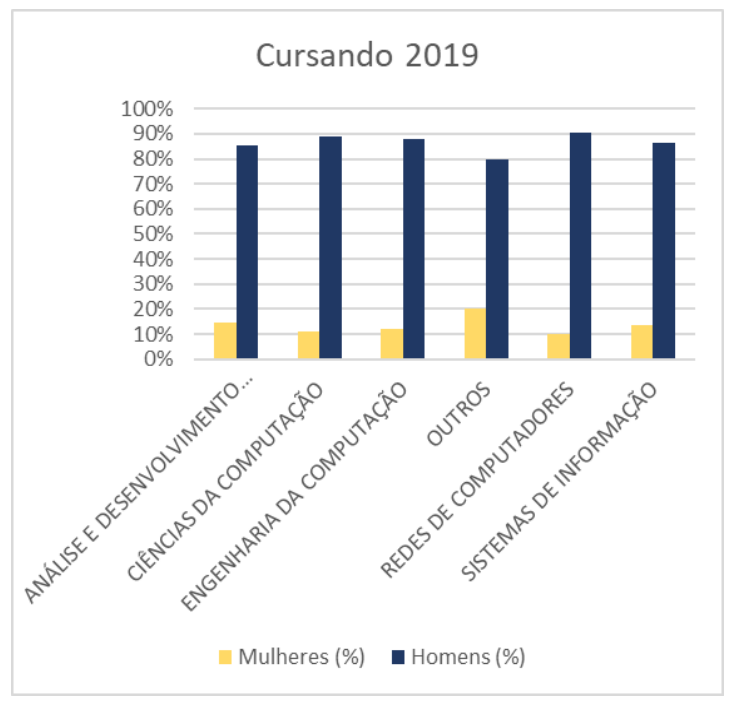

(B)

Figura 4. Porcentagem de mulheres e homens cursando TI em 2018 e 2019.

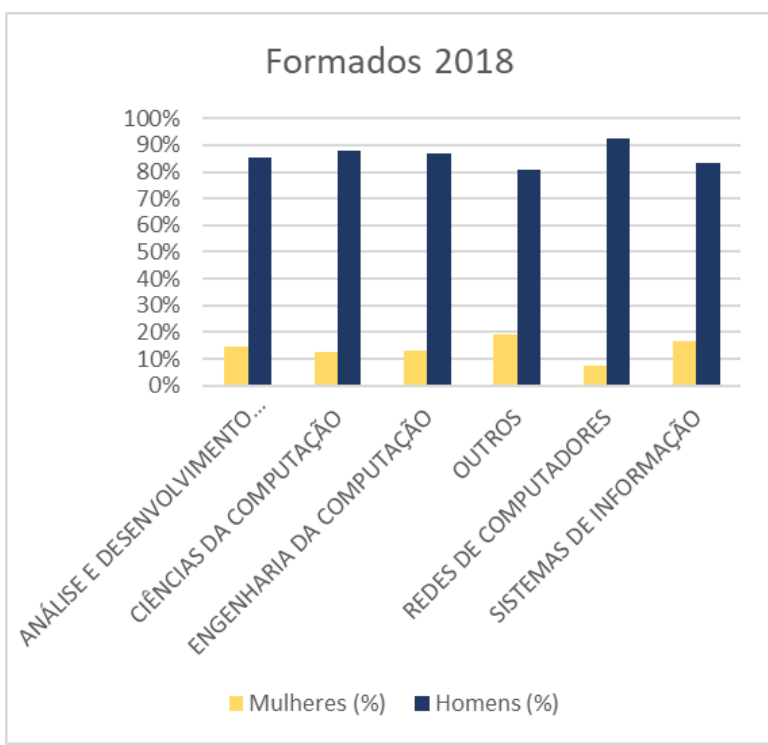

(A)

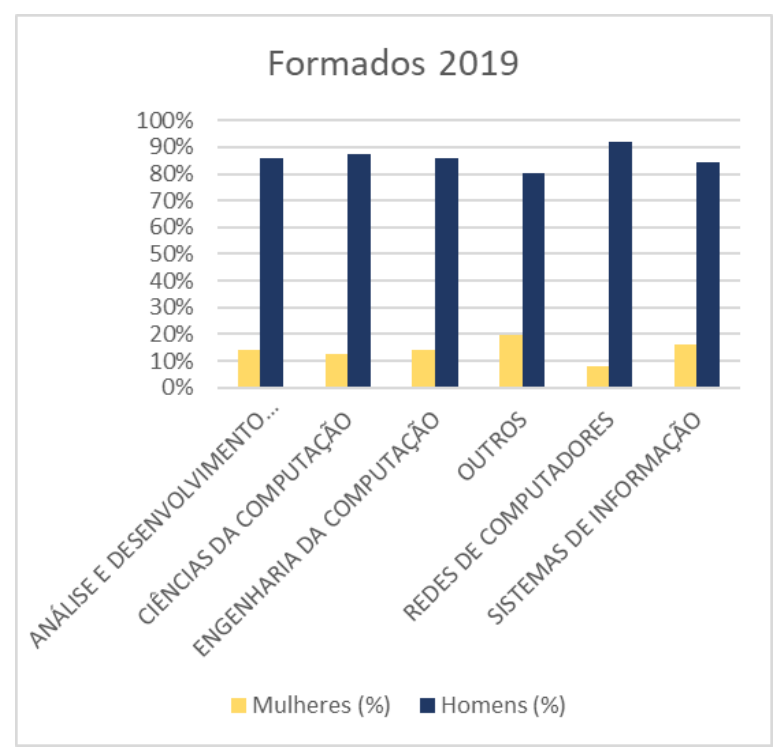

(B)

Figura 5. Porcentagem de mulheres e homens formados em TI em 2018 e 2019.

A Figura 6 exibe o gráfico do mapa do Brasil com o número de discentes femininas da área de TI, em cada estado, no ano de 2019. Observa-se que quanto mais escuro é o tom de azul, maior é o número de mulheres cursando TI naquele estado. Sendo assim, o estado com mais alunas de TI é São Paulo (SP) com o valor de 9.970, seguido de Minas Gerais (MG) com 2.777 e em terceiro lugar está Rio de Janeiro (RJ) com 1.877. Evidencia-se, dessa forma, que a região Sudeste se sobressai quanto ao número de estudantes de mulheres na área de TI com 51,9\%. Logo após tem a região 
Nordeste com índice $18,8 \%$, a região Sul com $12,8 \%$ e as regiões Centro-oeste e Norte empatadas com $8,3 \%$ e 8,2, respectivamente. Uma vez que a região Sudeste é a que oferece mais cursos de TI, isto é, $45 \%$ do total de cursos ofertados em todas as regiões, era esperado que o valor mais alto de estudantes estaria concentrado nesta região.

De forma semelhante, a Figura 7 exibe o gráfico do mapa do Brasil com o número de mulheres formadas na área de TI em cada estado brasileiro no ano de 2019. Novamente, os estados SP, MG e RJ possuem as taxas mais altas. Por outro lado, Roraima (RR) apresenta o menor número de meninas formadas em TI, que é o valor 12.

A comprovação da baixa representatividade feminina nos Cursos Superiores no Brasil, durante o período estudado, denuncia a histórica desigualdade de gênero, bem como reforça a necessidade de incentivar o acesso das mulheres a essas áreas.

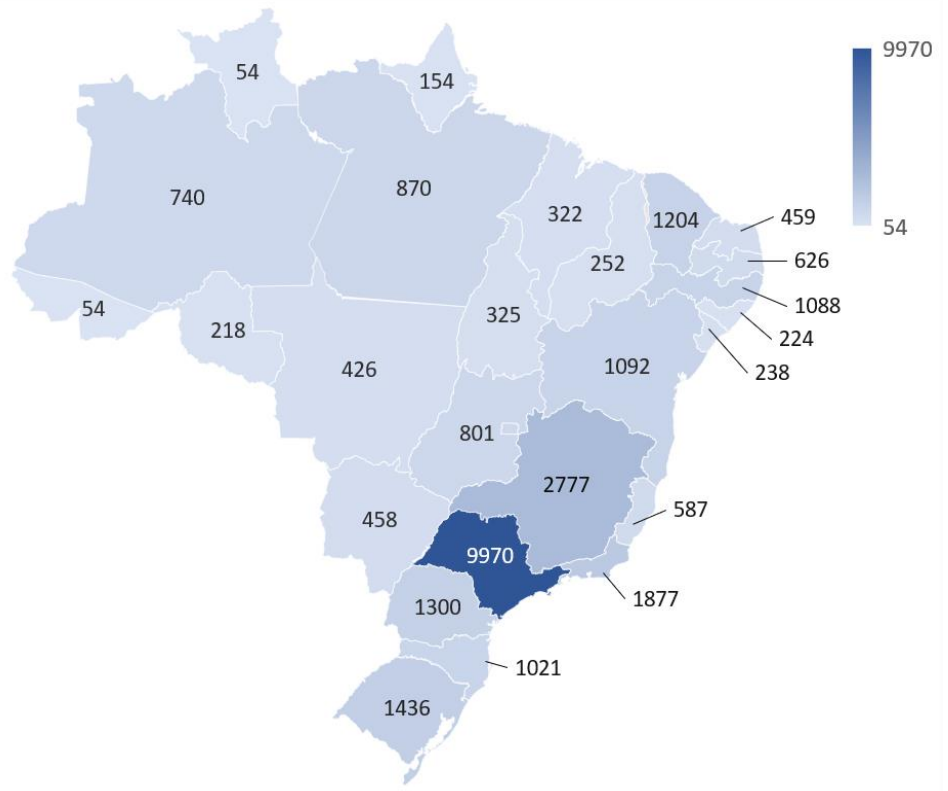

Figura 6. Mapa do Brasil exibindo o número de mulheres cursando TI em 2019.

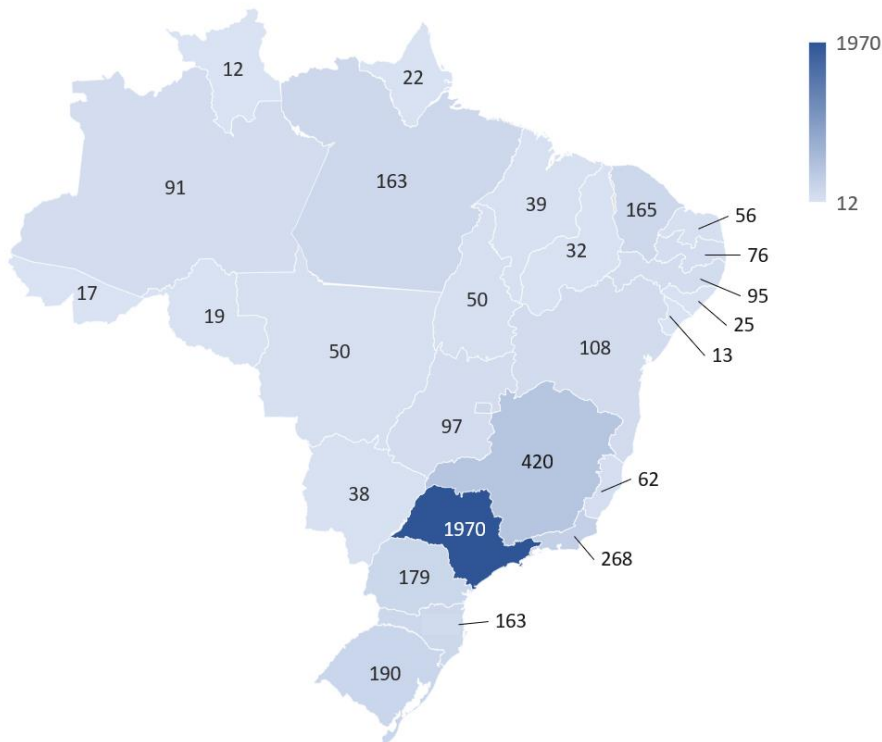

Figura 7. Mapa do Brasil exibindo o número de mulheres formadas em TI em 2019. 


\section{Conclusão}

Diante da disparidade quantitativa de mulheres e homens nos cursos da área de TI, surgiu a proposta deste trabalho que objetiva salientar o histórico da participação feminina na área de TI e destacar o cenário feminino atual dos cursos superiores de TI no Brasil, por meio de uma análise estatística dos microdados do Censo da Educação Superior, disponibilizados pelo INEP referentes aos anos de 2014 a 2019. Ao final da análise os resultados observados são a confirmação da desigualdade de gênero tanto no número de pessoas que estão cursando, quanto no número de formadas. Além disso, percebeu-se que os estados que possuem mais pessoas do sexo feminino na área de TI estão na região Sudeste.

O estudo produziu a descrição da evolução histórica das mulheres na TI, narrando a história de Ada Lovelace, das computadoras do ENIAC, assim como Hopper, Lamar, Sammet e Goldberg. Estas histórias destacam as questões de gênero, tecnologia e trabalho. Os conflitos entre as representações do trabalho das mulheres na computação garantiram a invisibilidade histórica delas. Mesmo nos casos em que foram fomentadoras da evolução tecnológica, esses trabalhos foram omitidos. Nesse contexto, coube a elas ocupações menos valorizadas socialmente, levando a crer que o trabalho feminino não é inovador.

Dessa forma, entende-se que a história da computação reflete os termos centrados no homem, resultando numa história distorcida do desenvolvimento tecnológico que tornou invisíveis as contribuições das mulheres e promoveu uma visão reduzida das capacidades das mulheres nesse campo. Essas histórias incompletas enfatizam a noção de que os trabalhos de TI são e foram atividades masculinas. Portanto, faz-se necessário escrever sobre a importância das mulheres na TI, narrar suas histórias na evolução tecnológica, da qual sempre fizeram parte, em ação e na memória.

\section{Referências}

Barton, R. (2010). Hedy Lamarr: the most beautiful woman in film. University Press of Kentucky.

Bittencourt, L. F. (2016). As programadoras do ENIAC apagadas da história da computação. Disponível em: <https://lfbittencourt.com/mulheres-programadoraseniac-b68503ef05f6/>, Acesso em: 21 mai. 2020.

Castro, B. (2013). Os gargalos para o ingresso e a permanência das mulheres no mercado de TI, no Brasil. In Conferencia Regional sobre la Mujer de América Latina y Caribe. CEPAL, Santo Domingo (Vol. 15, pp. 2018-2019).

CHM - Computing History Museum. Página institucional. California, EUA. Disponível em: $<$ https://computerhistory.org/>, Acesso em: 20 mai. 2020.

Fuegi, J., \& Francis, J. (2003). Lovelace \& Babbage and the creation of the 1843 'notes'. IEEE Annals of the History of Computing, 25(4), 16-26.

Graham-Cumming, J. (2010). Let's build Babbage's ultimate mechanical computer. New Sci.

Huskey, V. R., \& Huskey, H. D. (1980). Lady lovelace and charles babbage. Annals of the History of Computing, 2(4), 299-329. 
IEEE Computer Society. Página institucional. Washington, EUA. Disponível em: $<$ https://www.computer.org/>, Acesso em: 20 mai. 2020.

INEP. Página institucional. Disponível em: < http://portal.inep.gov.br/web/guest/microdados>, Acesso em: 01 jun. 2021.

Gil, A. C. (2008). Métodos e técnicas de pesquisa social. 6. ed. Ediitora Atlas SA.

Kay, A. C. (1996). The early history of Smalltalk. History of programming languages--II, $511-598$.

Light, J. S. (1999). When computers were women. Technology and culture, 40(3), 455483.

Lima, M. P. (2013). As mulheres na Ciência da Computação. Revista Estudos Feministas, 21(3), 793-816.

Louzada, C. S., Gomes, W. F., Nunes, M. A. S. N., Salgueiro, E. M., Andrade, B. T., \& Lima, P. S. (2014). Um mapeamento das publicações sobre o ingresso das mulheres na computação. In CLEI 2014: Conferência Latino-americana em Informática-VI Congresso da Mulher Latino-americana na Computação. Montevidéu (p. 16).

Maia, M. M. (2016). Limites de gênero e presença feminina nos cursos superiores brasileiros do campo da computação. cadernos pagu, (46), 223-244.

McCartney, S. (1999). ENIAC: The triumphs and tragedies of the world's first computer. Walker \& Company.

Mirkoski, M. L. (2018). Números e polinômios de Bernoulli.

Moreira, J. A., MATTOS, G. D. O., \& Reis, L. S. (2014). Um panorama da presença feminina na ciência da computação. Encontro Internacional da Redor-Rede Feminista Norte e Nordeste de Estudos e Pesquisa sobre a Mulher e Relações Gênero. Recife: EDUFRPE, 1, 3527-3542.

Nunes, D. (2018). Educaçao superior em computaçao, estatısticas 2017. Sociedade Brasileira de Computaçao-SBC, 7.

Oliveira, A., Moro, M., \& Prates, R. (2014, July). Perfil feminino em computação: Análise inicial. In Anais do XXII Workshop sobre Educação em Computação (pp. 179-188). SBC.

Sammet, J. E. (1969). Programming Languages; History and Fundamentals (No. 04; QA76. 5, S3.).

Schinzel, B. (2017). Women in computing and the contingency of informatics cultures. In Informatics in the Future (pp. 87-98). Springer, Cham.

Stein, D., \& Ada, A. (1985). A Life and a Legacy. Mit Press.

Wazlawick, R. S. (2017). História da computação. Elsevier Brasil.

Williams, K. B. (2012). Grace Hopper: Admiral of the cyber sea. Naval Institute Press.

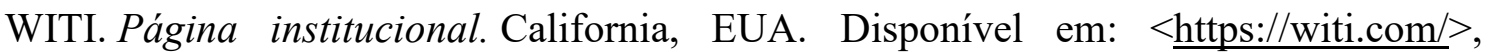
Acesso em: 20 mai. 2020. 